The first paper in this issue has been written by Penelope Hawe. Penny is not only a leading figure in developing the concept of capacity building in Australia, but is also an international expert in this field. Her article provides a lucid introduction, describing what is meant by capacity building.

One area of application and development of the idea of capacity building is in international health, and the article by Jan Ritchie and her colleagues at the University of New South Wales describes their application of capacity building to consultancy work in the Pacific Islands. Their article describes how an educational approach to improve health in developing countries needs to be extended to encompass a broader capacity building strategy.

Doris Zonta and Andrew Wilson have adopted an organisational perspective, and are concerned with the development of the infrastructure required for an effective public health system. The Health Promotion Strategies and Settings Unit of the NSW Department of Health has been very active over the last few years in fostering a climate of inquiry and investigation about capacity building. A summary of the initiatives that they have undertaken is presented in the article by Shelley Bowen.

Driven by both the need to develop stronger infrastructure and the need for community understanding and acceptance, the newly emerging field of mental health promotion has enthusiastically embraced the concept of capacity building. Kym Scanlon and Beverley Raphael discuss the contributions of organisational capacity, workforce development and community capacity to an overall strategy for promoting mental health.

Different individuals and organisations take up new ideas at different rates. While there is always a small group who enthusiastically takes up new ideas quickly, this by itself is generally insufficient to produce system-wide uptake. To ensure systematic and monitored uptake of capacity building strategies, the Health Promotion Strategies and Settings Unit has embarked on a dissemination strategy. In the final article Linda Cristine describes the grants scheme that is being conducted to test the applicability of the capacity building indicators in a variety of projects and settings throughout NSW.

\title{
CAPACITY BUILDING: FOR WHAT?
}

\section{Penelope Hawe}

Department of Public Health and Community Medicine University of Sydney

The words 'capacity building' have spread rapidly throughout the health system, almost like a virus. But what exactly does capacity building mean? How did the term originate? What difference will or should capacity building make to the business of running health services? This article will briefly overview what we expect to achieve by promoting capacity-building as a strategy and how we might measure our success in doing so.

\section{NEW CONCEPT OR NEW JARGON?}

The Oxford English Dictionary defines 'capacity' as 'holding-power', as in a vessel filled to capacity'. In NSW, health workers have spoken about capacity building as helping to realise 'potential'. ${ }^{1}$ These definitions refer to increasing the strength, capability or power of something. But to do what? In the health system capacity building refers to at least two things:

- our capacity to deliver specified, high quality services or responses to particular (familiar) situations or problems, such as in our cancer control capacity;

- capacity of a more generalised nature-the capacity of the system we are working in to solve new problems and respond to unfamiliar situations.
The first type of capacity is defined by set criteria around particular competencies relating most often to specific skills, procedures and structures (such as setting up a Pap screening service)..$^{2-4}$ The concern is with how well a particular service is delivered and its appropriateness for population needs. The second type of capacity is defined by more diffuse and complex criteria, such as the characteristics of the work environment, the nature of our team interactions, the quality of leadership, and the way our health organisations are structured. ${ }^{5,6}$ It addresses how adequately the environment we are working in encourages us to think creatively, to adapt to change, to innovate and to solve problems.

So, capacity building is most definitely not new. Words like performance standards, competency assessment, and quality improvement easily cover the first type of capacity; and words like leadership development, service development, team development, workforce development, and organisational development cover the second type. What perhaps is new, given the attention capacity building has at present, is the emphasis on issues of measurement. This has meant that the vagaries of the concept have had to be confronted. ${ }^{7}$ In an era where we are heavily focussed on health outcomes, the resources going into achieving those outcomes have come under increased scrutiny. While changes in health outcomes at a population level will ultimately tell us whether or not we have an effective health system, intermediate indicators-indicators of our 
success with capacity building-will tell us if we are building a system that is likely to be effective. As changes in health outcomes at a population level are often slow to materialise, changes in more intermediate indicators may suggest where more immediate remedial action is necessary.

\section{WHAT ABOUT COMMUNITY DEVELOPMENT? IS IT THE SAME AS CAPACITY BUILDING AT A COMMUNITY LEVEL?}

Again there are two ways capacity building operates at a community level. Where community-level interventions have been proven to be effective, researchers and practitioners have tried to sustain programs, and devise measures to assess how well a program has been sustained. ${ }^{8}$ This can be thought of as a way of maximising the benefit of an intervention by ensuring its ongoing capacity to deliver health gains. Trying to conceptualise and then measure how, for example, initiatives in cardiovascular health have been promulgated across local communities and health regions, is the subject of a 10-year program of research and development in Canada. ${ }^{9}$

At a broader level, one would think a community that has been successfully involved in an extensive cardiovascular health initiative may have picked up a few clues about how to work on other issues as well. ${ }^{10}$ That is, experience in health promotion at a community level may help build a more generalised capacity of the type we have been calling problem-solving capacity. The organisations that have been brought together can use these links to establish new plans and activities. Community residents may have become more articulate and skilled in expressing their needs and acquiring resources. Indeed, it is held that developing skills and capacities in communities to affect the issues and decisions that affect their health is what health promotion is all about. ${ }^{11-12}$ This is particularly important when we acknowledge the social determinants of health. In that sense community development and capacity building at a community level are the same, where issues determined by the community itself drive the agenda.

\section{SO WHAT CAN BE MEASURED AND WHY?}

While we can explain what capacity building is, and what outcomes we might expect as a result, the concept feels slippery when it comes to precise measurement. However, in this sense our situation is no different than when researchers first started to come to grips with measuring, say, the quality of life. At one time when the only 'hard data' was mortality, to factor-in quality of life seemed fanciful. But these days, for decision-makers not to assess the affect on quality of life when weighing up the options between treatment choices would be virtually negligent. In the same sense, researchers and practitioners who have been grappling with capacity building are slowly building a consensus of how it might be measured., ${ }^{713-19}$ These measures could be used to recognise and guide capacity building while it is being conducted (that is, to monitor the process) and allow decision makers to factor in capacity building outcomes when weighing up options for health interventions at a population level. For example, one could compare program A which might cost $\mathrm{Y}$ and deliver $\mathrm{Z}$ in the way of health outcomes, with program $\mathrm{B}$ which might cost $\mathrm{X}$ and also deliver $\mathrm{Z}$ in the way of health outcomes, but also might deliver a range of outcomes in capacity building such that one would have reason to believe that the $\mathrm{Z}$ level of health outcomes would be sustained and multiplied over time. This is how being able to pin down, specify and measure our efforts in capacity building will affect resource decisions.

The concepts being made operational and measured in indicators of capacity building are various and include: the assessment of structures for accessing information and making decisions, resource commitments, leadership skills, skills in the execution of particular tasks, the presence of certain policies and organisational goals, and the linkage structures across organisations. ${ }^{7,13-19}$

\section{WHERE TO FROM HERE?}

Progress depends on a high level of participation and willingness for the diversity of people involved in the health workforce to relate these ideas to their own work and become constructive critics and contributors to the process of making capacity building a concrete, recognised and valued part of our activities. It is a creative task.

\section{REFERENCES}

1. Hawe P, King L, Noort M, Gifford SM, Lloyd B. Working invisibly: health workers talk about capacity building in health promotion. Health Promotion International 1998. 13(4):285295.

2. Roper WL, Baker EL, Dyal WW, Nicola RM. Strengthening the public health system. Public Health Rep 1992.107:609615.

3. Meissner HI, Bergner L, Marconi KM. Developing cancer control capacity in state and local public health agencies. Public Health Rep 1992. 107:15-23.

4. Schwartz R, Smith C, Speers MA. Capacity-building resource needs of state health agencies to implement community-based cardiovascular disease prevention programs. J Public Health Policy 1993. 14:480-494.

5. Argyris C. On Organisational Learning. Oxford: Blackwell, 1992.

6. Simnet I. Managing Health Promotion. Developing Healthy Organisations and Communities. Chichester: John Wiley and Sons, 1995.

7. Hawe P, King L, Noort M, Jordens C, Lloyd B. Indicators to help with capacity building in health promotion. NSW Department of Health and the Australian Centre for Health Promotion, Department of Public Health and Community Medicine, University of Sydney, 2000.

8. Rissel C, Finnegan J, Bracht N. Evaluating quality and sustainability issues: issues and insights from the Minnesota 
Heart Health program. Health Promotion International 1995. 10:199-207.

9. Stachenko S. The Canadian Heart Health Initiative: dissemination perspectives. Can J Public Health 1996. 87 Suppl 2: S57-59.

10. Hawe P, Noort M, King L, Jordens C. Multiplying health gains: the critical role of capacity building in health promotion. Health Policy 1997. 39:29-42.

11. Israel BA. Social networks and social support: implications for natural helper and community level interventions. Health Educ $Q$ 1985. 12: 65-80.

12. Minkler, M. Community Organization and Community Building for Health. New Brunswick: Rutgers University Press, 1997.

13. Wickizer TM, Von Korff M, Cheadle A. Activating communities for health promotion: a process evaluation method. Am J Public Health 1993. 83:561-567.

14. Goodman RM, Speers MA, McLeroy K, Fawcett S, Kegler M, Parker E, Smith S, Sterling T, Wallerstein N. An initial attempt to identify and define the dimensions of community capacity to provide a basis for measurement. Health Education and Behaviour 1998. 25(3):258-278.
15.Jackson SF, Cleverly S, Poland B, Robertson A, Burman D, Goodstadt M, Salsberg L. Half Full or Half Empty? Concepts and Research Design for a Study of Indicators of Community Capacity. Ontario: North York Community Health Promotion Research Unit, City of North York Public Health Department, 1997.

16. Handler A, Turnock BJ, Hall W. A strategy for measuring local public health practice. Research and measurement in public health. Am J Prev Med 1995. 11(Supplement 2):29_ 35.

17. Miller CA, Moore KS, Richards TB, McKaig C. A screening survey to assess local public health performance. Public Health Rep 1994. 109(5):659-664.

18. Miller CA, Richards TB, Christenson GM, Koch GG. Creating and validating practical measures for assessing public health practices in local communities. Am J Prev Med 1995. 11:Suppl 2:24-28.

19. Richards TB, Rogers JJ, Christenson GM, Miller CA, Gatewood DD, Taylor MS. Assessing public health practice: application of ten core function measures of community health in six states. Am J Prev Med 1995. 11:Suppl 2:36-40. ⿷匚

\section{INDICATORSTO HELP PLANNING AND EVALUATION OF CAPACITY BUILDING IN HEALTH PROMOTION}

The Capacity Building Process and Outcomes Indicator Project, Department of Public Health and Community Medicine, University of Sydney, developed nine checklists for use in planning and evaluation:

- the strength of a coalition

- opportunities to promote incidental learning among other health workers

- opportunities to promote informal learning among other health workers

- whether a program is likely to be sustained

- the learning environment of a team or project group

- capacity for organisational learning

- capacity of a particular organisation to tackle a health issue

- the quality of program planning

- community capacity to address community issues.

Source: Hawe P, King L, Noort M, Jordens C, Lloyd B. Indicators to help with capacity building in health promotion. NSW Department of Health and the Australian Centre for Health Promotion, Department of Public Health and Community Medicine, University of Sydney, 2000.

\section{CAPACITY BUILDING FOR INTERNATIONAL HEALTH GAINS}

Jan Ritchie, Sally Nathan and Ann Mehaffey

School of Medical Education

University of New South Wales

This article describes the recent experiences of the School of Medical Education, at the University of New South Wales, in working with Pacific Island countries, and draws those experiences together with some lessons from the published literature to propose a set of key principles that relate to capacity building. Capacity building is a key component of international health development and is a primary activity in the School of Medical Education at the University of New South Wales (UNSW), one of three 